\title{
ANALYSIS OF YOUTH ACTIVITIES IN THE DIGITAL AGE: TIME-GEOGRAPHICAL APPROACH
}

\author{
Alexandra V. Starikova ${ }^{1}{ }^{*}$, Elena E. Demidova ${ }^{2}$ \\ 'Institute of Geography, Russian Academy of Sciences, Moscow, Russia \\ Lomonosov Moscow State University, Moscow, Russia \\ *Corresponding author: a.v.starikova@igras.ru \\ Received: May 25 th 2020 / Accepted: February 16 th 2021 / Published: April 1 $1^{\text {st }}, 2021$ \\ https://DOI-10.24057/2071-9388-2020-99
}

\begin{abstract}
The study analyses daily activities of youth in the virtual and actual environment within the framework of theoretical and applied achievements of time geography. The role of mobile devices in youth life, transformation of traditional activity and changes in the daily organization of actions due to digitalization are discussed. Empirical data for the research were obtained via a diary method (the respondents were 18-22-year-old students). Features of individual daily foreground and background activities, digital devices used, activities relation and localization are evaluated by geovisualization performed within the time-geographical concepts. Regardless of the smartphonization, individuals reserve time spans not associated with virtual activities; their online activities are localized within places of residence, study and traffic routes, while public spaces serve as "live communication" platforms (but a complete rejection of virtual activity does not occur here). An attempt to compare youth daily activity under ordinary conditions and during the period of forced isolation during the COVID-19 pandemic is being made.
\end{abstract}

KEY WORDS: digitalization, smartphonization, time geography, diary method, youth, everyday life, COVID-19

CITATION: Alexandra V. Starikova, Elena E. Demidova (2021). Analysis Of Youth Activities In The Digital Age: TimeGeographical Approach. Geography, Environment, Sustainability, Vol.14, No 1, p. 234-240

https://DOI-10.24057/2071-9388-2020-99

ACKNOWLEDGEMENTS: Geovisualization of students' diaries was fulfilled by A.V. Starikova within the framework of the stateordered research theme of the Institute of Geography RAS, no. 0148-2019-0008.

Conflict of interests: The authors reported no potential conflict of interest.

\section{INTRODUCTION}

In the $21^{\text {st }}$ century, it is hard to find a sphere of life not affected by digitalization. Entire systems of various levels are created based on digital processes - from Smart City and Smart State to Smart Body and Internet of Things (Demidova 2018). However, digitalization is not just a technological process. It starts to reformat many socioeconomic systems, affects and often drastically changes traditional models of society functioning. Time-space activity patterns of people also change due to modern information and communication technologies (ICT) (Shaw 2009) as they go to a "temporally and spatially fragmented lifestyle" (Ben-Elia et al. 2018). These technologies determine more and more how we work, study, buy goods and services, travel, and finally how we communicate with each other. For example, the expansion of smartphones has provoked people to restructure their everyday life in terms of time and space use (Ling 2012), while modern transport means saturated with additional functions (like access to the Internet) imposed virtual environment on individuals (Ben-Elia et al. 2018), etc.

These processes have become especially important during the COVID-19 pandemic. The public environment was dramatically affected by COVID-19. Under the quarantine, citizens' physical movement and personal communication were minimized. Throughout the world, including Russia, forced isolation has led to the significant growth in the use of digital devices and services as well as obvious changes in the digital behaviour of users. Internet connection has become an essential condition for maintaining the usual life activities for millions of people. The consequences of the sudden "forced" digitalization we have yet to evaluate. And the main question has to do with what 'digital behaviour' models we will inherit from the COVID-19 era.

In the digitalization process (including smartphonization) the established connections between such fundamental concepts in human life as "activity," "place," and "time" are changing completely, which was pointed out by multiple researchers including geographers (Couclelis 2009, Ellegård 2018). The environment where physical and virtual features are mixed is called cyberspace (Kwan 2001). Cyberspace inhabitants are provided with a special capability-human extensibility, which allows them by means of transport and communication not only to overcome the problem of long distances but also to be situated simultaneously at various points on the timeline. The human extensibility concept was introduced almost fifty years ago (Janelle 1973), but its relevance is only growing: people maintain the opportunity to work, study, do not give up leisure and social contact, etc. (especially in the context of the COVID-19 pandemic).

The population category that is the most susceptible to the digital era trends and ICT achievements is the youth. This specific age group comes in contact with such phenomena as increasingly larger role of new work 
statuses', expansion of sharing economy (such services as BlaBlaCar, et al.), crowdfunding platforms, etc. (Markova 2019). Digitalization also affects youth's social life (Aralina and Ben'ko 2015). Today large parts of their social contacts and interaction with friends have moved to virtual space, and now (compared with the early 2000s) social relations are more independent from fixed places and times (Thulin et al. 2019). According to some studies, young people (this means Millennials here) check their phone 150 times per day, browsing text messages, social media posts and e-mails (Brandon 2017). It is not surprising that during the COVID-19 pandemic the youth (16-24-year-olds) demonstrate the highest social contact virtualization rates (up to 60\%) (Digital 2020: April... 2020).

Digitalization and smartphonization are under constant observation by scientists including representatives of socioeconomic geography. Among Russian scientists, attention is paid mainly to the digital economy (Blanutsa 2019, Markova 2019, etc.), while researches dedicated to the Internet, fixed-line and mobile communications' development in the country as a whole and on the regional level are less common (Nagirnaya 2018). Digitalization and its geo-visual aspects in terms of human everyday life and activity in the hybrid physical-virtual space are generally not covered in the Russian works.

In this study, the geographical analysis of youth daily activities in virtual and physical space is done based on the theoretical and applied research in the field of time geography. It deals with issues of correlation between foreground and background activities and application of various mobile gadgets during those activities. An attempt is being made to compare the youth daily activity in real and virtual space under ordinary conditions and during the forced isolation period.

\section{MATERIALS AND METHODS}

A study of new socioeconomic phenomena, including smartphonization, requires approachescapable ofreflecting the intensive penetration of digitalization in various areas of life. In our opinion, one of the most effective approaches among the existing ones is a time-geographical approach, which, as part of social geography, is primarily aimed at personal behaviour analysis (Ellegård 1999, Lenntorp 1999). However, it is not locked on this level and may be used for the whole process of public interaction (groups of people, households) and activities (the full range requiring direct human participation) within a certain territory (Pred 1977). Time geography objects include people and any objects or phenomena represented in the space-time domain (Carlstein et al. 1978, Lenntorp 1999). The subject of timegeographic research is life dynamics, or, more specifically, the human and social functioning.

Studies of human activity in time geography are based on several basic concepts introduced by the famous Swedish geographer Torsten Hägerstrand fifty years ago (Ellegård, 2019). The central concept is the path-a motion pattern of an individual in space-time (within the framework of daily, weekly, annual and other cycles up to whole life). Each path consists of elementary events (move, arrive, stay, leave, etc.). It reflects individuals' movement patterns and allows to analyse their actions and interaction with each other (Lenntorp 1999). The main events on the path take place when the trajectories of different people intersect on the way or in the same place (i.e., at stations), forming activity bundles together with individuals' belongings, equipment and other resources (Hägerstrand 1970). When an intersection occurs in order to achieve a specific goal (for example, production of industrial or agricultural outputs), a project (an activity with a certain sequence of tasks, involving the unification of people, resources, premises or territories in space-time) arises (Hägerstrand 1985).

Initially, the method of graphical analysis was recognized as one of the strong points of time geography that was stressed by its followers and opponents and always specified even by the critics when speaking about its representative potential (Hallin 1991). Analysis of spatiotemporal data on living and activities of people with the help of Hägerstrand's models combines spatial coordinates (position on a two-dimensional map) with the timeline. To a great extent, it facilitates problem-definition and problem-solving in research. Hägerstrand's spacetime prism is considered to be one of the most successful examples of time integration into geographical analysis.

The development of the time geography concept experienced a rapid rise, decline and a new rise that occurred at the $20^{\text {th }}-21^{\text {st }}$ centuries' cusp (Starikova and Treivish 2017). The "revival" of this approach is associated not only with the development of ICTs and expansion of access to new data types ${ }^{2}$ but also with the emergence and development of new time geography. In contrast to the classic time geography that originated in the 1970s in the studies of the Lund School, the new time geography puts the stress on exploring digital aspects of human life when physical movement is accompanied by a simultaneous perception of audio-visual data and mobility in a virtual world (so-called hyper-mobility) (Gillespie and Richardson 2000). Specifically, in the new time geography framework the foreign researchers actively address the issues related to the geographic presentation of virtual-actual environment. The Hägerstrand's patterns of space-time paths have been brought up to date in the framework of the new time geography. Now individuals'space-time behavior and their paths and interactions are modeled in a multidimensional space (in classical time geography space-time path is constructed in three-dimensional space) (Couclelis 2009). Geovisualization of daily human activities based on new space-time schemes allows to analyse individual and group activities both in geospace and virtual space with the focus put both on space and time. The latter is viewed as a resource equal in importance or sometimes even more important than financial and material resources (Kramer 2004).

The geovisualization in this work is based on the spacetime schemes suggested by geographers who studied the interrelation between foreground and background activities in the life of Swedish youth (it is related primarily to "life" in a virtual environment) (Thulin and Vilhelmson 2019). The main elements of the schemes are space-time path within a framework of circadian cycle of activities ${ }^{3}$ and two connected bar charts reflecting time spent on different foreground activities (offline and online) and background online social contacts with friends. In our research we consider not only social contacts: our schemes show different types of foreground and background activities (divided into categories) both in physical and virtual spaces.

${ }^{1}$ Freelance, remote working, i.e., forms of labour that due to the Internet are not rigidly fixed to time and location.

'For example, the mobile operators' data on subscribers' movement, which means an increase in the ability to analyse the activities of people.

${ }^{3}$ It is important to note that individuals have to return home in the evening for repose, meal, rest and comfort after a day spent somewhere else (Lenntorp 1976). 
The materials for youth daily life analysis were collected by applying a diary method. The diaries of 18-22-year-old respondents (17 respondents, all of them the students of faculty of geography in the Lomonosov Moscow State University) obtained in 2018-2019 served as the quality data source. The application of the diary method allowed forming a clear view on how youth daily activities are organized within 24 hours on workdays and holidays. The respondents noted in chronological order what activities they conducted at what time and where, were they alone or doing something with other people, and also whether they used any digital gadgets during this activity, including personal computers (PCs), smartphones, iPads, etc. (and if so, with what purpose) (Table 1).

Each respondent filled out a diary for two workdays and one holiday, which revealed youth behavior in physical-virtual space for different schemes of daily life organization. On workdays, a respondent is obliged to act according to a certain timetable, while on holidays a day can be planned following individual preferences. Observation of two workdays helps to catch how the main foreground activity (study) combines with other (nondaily or irregular) activity types (a side job, etc.) in actual and virtual space. The capability of the time-geographical approach to visualize life in hybrid physical-virtual space was demonstrated on the example of two most detailed diaries ${ }^{1}$.

Data geovisualization we practiced allows: to analyse activity in virtual space (the study of this activity by other methods is associated with a number of problems); to single out the foreground and background activities; to rate interrelation of foreground and background activities within 24 hours as well as the difference in activity types on workdays and holidays; to geo-reference of various activity types.

\section{RESULTS AND DISCUSSION}

According to the studies of the International Telecommunication Union (ITU) ${ }^{2}$, the Pew Research Center ${ }^{3}$ and We Are Social Agency, only approximately $17 \%$ of the world population used the Internet in 2005. Between 2005 and 2020, the number of Internet users was growing by $10 \%$ a year on average and by 2020 it has reached almost 60\% of the population (over 4.5 bln people) (Measuring... 2019, Digital 2020: April... 2020, Digital 2020: Global... 2020). In Russia, the number of Internet users has also significantly increased since the beginning of the 21 st century. Now about three-quarters of the Russian population use the Internet (in 2000 it amounted to $3 \mathrm{mln}$ people and has reached $110 \mathrm{mln}$ people by the beginning of 2018) (Nagirnaya 2018). Compared to April 2019, in April 2020, the global Internet audience has increased by more than $7 \%$ (over $300 \mathrm{mln}$ people), and the number of active social media users increased by almost 9\% (Digital 2020: April... 2020).

Not so long ago it has been widely accepted that technological progress and development of global computer networks results in a decrease in individuals' physical activity (Kramer 2004). This conviction was based on an assurance that people will spend more time at stationary PCs. However, it became clear that mobile gadgets expansion removes restrictions on spatial movement and allows to maintain online activity at any location of the world (provided an individual has certain technical tools and gadgets). Thus, in 2018 about 72\% of Russia's adult population used mobile devices to access the Internet from home or workplaces; over $80 \%$ of these devices were mobile phones and smartphones (Abdrakhmanova et al. 2019).

The first pocket PC (the name of the first smartphone) was produced by the US IBM company in 1992, while the "smartphone" concept was introduced by Swedish company Ericsson in 2000. However, a true revolution in this field was made by Apple company when they released a gadget in a form of a monoblock unit in 2007. A smartphone became the most

Table 1. Fragment of a respondent's workday diary

\begin{tabular}{|c|c|c|c|c|c|c|}
\hline Time & What am I doing? & Where I am? & $\begin{array}{l}\text { Who is nearby? } \\
\text { Who am I } \\
\text { interacting with } \\
\text { now? }\end{array}$ & $\begin{array}{c}\text { Do I use } \\
\text { electronic } \\
\text { devices } \\
\text { (PC, laptop, } \\
\text { smartphone, } \\
\text { etc.)? }\end{array}$ & $\begin{array}{c}\text { For what } \\
\text { purpose do I } \\
\text { use electronic } \\
\text { devices? }\end{array}$ & Comments \\
\hline 09:00 a.m. & I wake up & At home & With family & No & - & - \\
\hline 09:05 a.m. & $\begin{array}{l}\text { I wash my face, make my bed, } \\
\text { exercise, take a shower }\end{array}$ & At home & With family & No & - & - \\
\hline 09:30 a.m. & Making breakfast & At home & With family & Smartphone & $\begin{array}{l}\text { Listing to music, } \\
\text { watching videos }\end{array}$ & - \\
\hline 10:05 a.m. & $\begin{array}{c}\text { I am combing my hair, getting } \\
\text { dressed, etc. }\end{array}$ & At home & With family & Smartphone & $\begin{array}{c}\text { Checking } \\
\text { social media } \\
\text { notifications }\end{array}$ & - \\
\hline 10:20 a.m. & $\begin{array}{c}\text { I am leaving home, going to } \\
\text { university }\end{array}$ & $\begin{array}{l}\text { In public } \\
\text { transport }\end{array}$ & Alone & Smartphone & $\begin{array}{l}\text { Listing to } \\
\text { podcasts/music }\end{array}$ & - \\
\hline 10:50 a.m. & $\begin{array}{l}\text { I am listening to a lecture/ } \\
\text { participate in a seminar }\end{array}$ & In the university & With classmates & Smartphone & $\begin{array}{l}\text { Taking pictures } \\
\text { of slides }\end{array}$ & - \\
\hline
\end{tabular}

${ }^{1}$ It does not pretend to be an illustration of a general Russian youth daily life organization. Such a generalization is possible only using a large sample of respondents. It may be one of the tasks in continuation of authors'studies.

${ }^{2}$ TTU is a specialized agency of the United Nations that is responsible for issues that concern information and communication technologies.

${ }^{3}$ Pew Research Center is an American research institute (think tank), which provides information on social issues, public opinion and demographic trends shaping the United States and the world. 
multifunctional gadget among many other items surrounding a man. A present-day smartphone, besides telephony that was its main function, serves as a PC, a camera, a day planner, an alarm clock, a navigator, a music player, a tool for ordering goods and services, etc. According to the study (Smartphone... 2019), in 2018 60\% of the world population used smartphones in daily life. In Russia the number of smartphone users accounts for $59 \%$ of adult citizens (Fig. 1) and, as expected, the most active group is the youth.

The answers of the respondents from our research also indicate that students use smartphones in their daily life more often than PCs, favouring a gadget that is capable of serving an exceedingly wide sphere of functions. PC plays a role of an instrument for doing training assignments (especially if this cannot be done by a smartphone, for example, when special software can be installed on a PC only) or is used at a workstation in the office.

In April 2020 over three-quarters of respondents reported an increased impact of mobile devices (primarily smartphones) in their lives and their usage time during the isolation in quarantine (Digital 2020: April... 2020). The full range of leisure activities has expectedly moved to the virtual environment compared to the same period in 2019: 57\% of respondents noted an increase in the time for watching shows and films on streaming platforms; $40 \%$ for listening to music; 35\% for computer and video games. A larger part of social contacts underwent virtualization. Almost half of respondents (46-47\%) acknowledged a significant growth of communication by social media and instant messenger services' ${ }^{1}$. The highest rates (up to $60 \%$ ) were demonstrated by young people (16-24-year-olds). Besides, for solving different impromptu problems produced by the pandemic, the number of users of previously not so typical applications for videoconferencing (Zoom, Microsoft Teams, etc.) has sharply risen. A new digitalization wave has also transformed those areas that were traditionally kept in the real-world environment: labour activity, education, medical industry, social services and assistance, etc. Every fifth online user plans to stay active in the virtual environment even after the restrictions will be lifted. Because of that, it is important to trace the changes in the digital behaviour of high-tech devices users during the pandemic and after it. For example, today we can assume the difference between a sequence and a set of activities on a student standard workday and its transformation during the forced isolation period: time spent in virtual space is growing, activities related to it are coming to the fore, replacing communication and entertainment outside the home (Fig. 2).

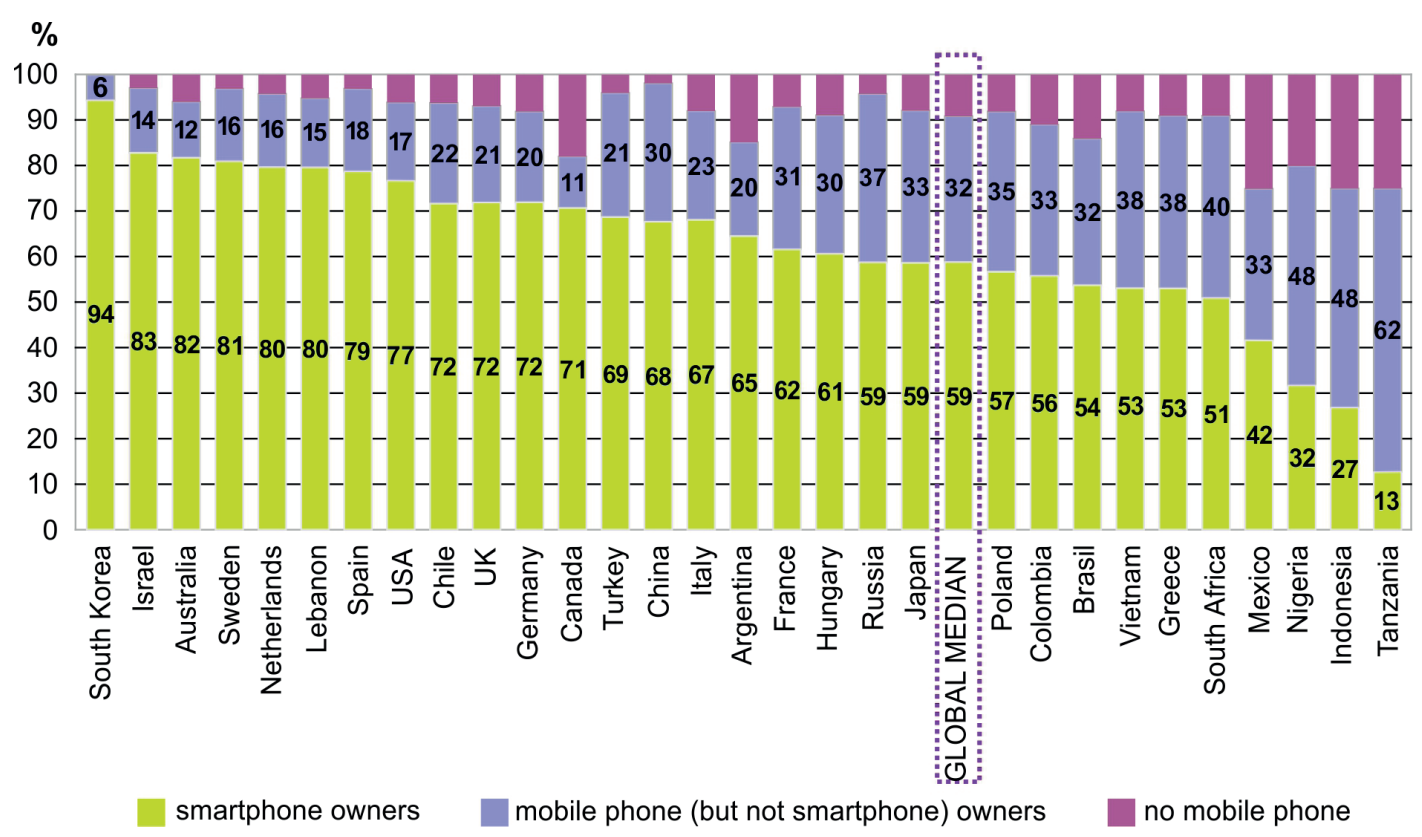

Fig. 1. Adult population owning smartphones and mobile phones (cellphones) in some developed and developing countries, \%, 2018. Compiled from (Smartphone... 2019)
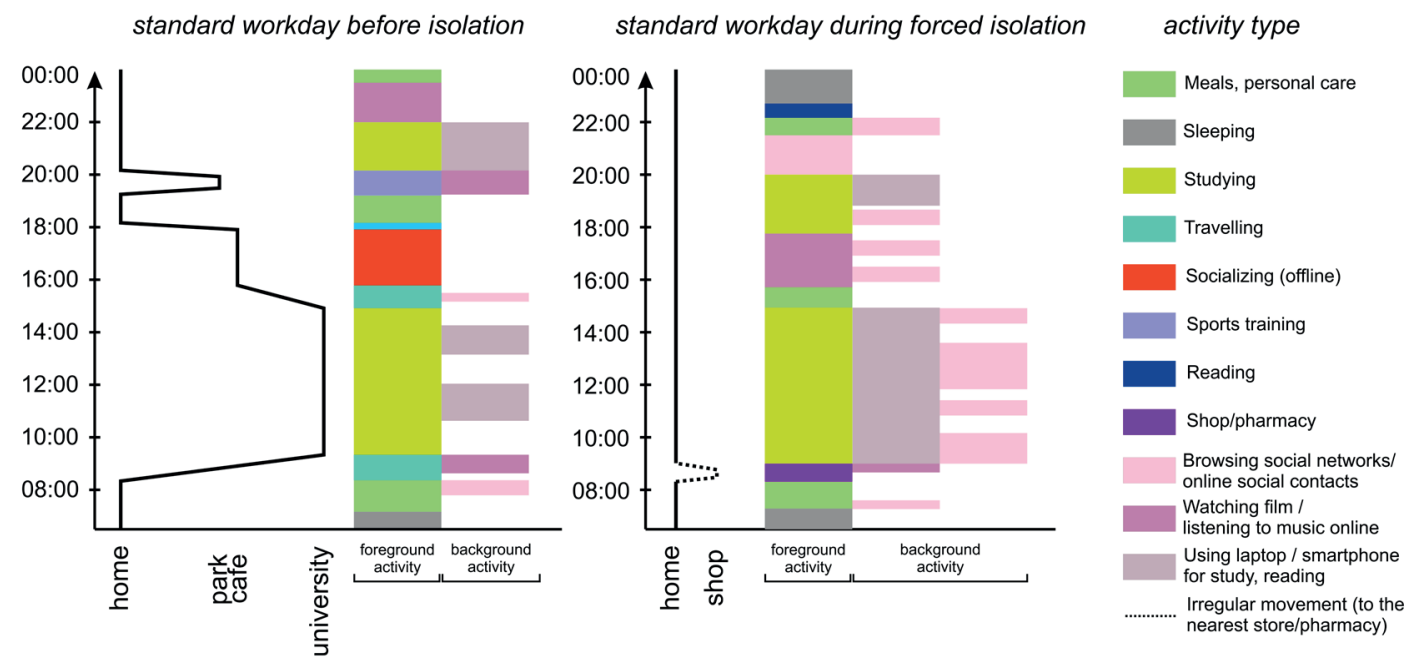

Fig. 2. Activities of a student on a standard workday and on a workday during forced isolation in COVID-19 quarantine

'Facebook, WhatsApp, Instagram, TikTok, etc.; in Russia one should add to this list VKontakte and OK.ru social networks. 
The study of activity in the virtual environment is associated with a number of problems, such as complication in surveillance and its measurement parameters (Thulin and Vilhelmson 2019). Geovisualization of individual daily life in the time geography framework to a great extent facilitates solving of this problem. In our research, respondents' activity in the virtual environment was divided into the following categories: activities in social networks (interaction, news screening, posting, commenting, etc.); audio-visual content consumption (viewing various types of content, listening to music, etc.); web surfing associated with online searching, including those for the study and work purposes.

According to the analysis of respondents' diaries, we can note that during the normal time youth activity in a virtual space (regardless of active use of mobile gadgets) remains mostly a background activity. "Life" in the virtual world so far rarely comes to the foreground even among this age group. We can consider the organization of Russian students' daily life to be exemplified by two time-geographical visualizations of respondents' dairies: a 19-year-old woman and a man of 22 years. Thus, Fig. 3 demonstrates that on workdays the female respondent allocates approximately an hour just once a day for purposeful social networks screening; however, on weekend online communication and virtual events acquire more value for her, summing up to more than two and a half hours divided into several slots of different length.

Nowadays an average Internet user spends online 6 h 43 min daily (almost a third of the waking hours!) (Digital 2020: Global... 2020). It is fair to assume that a major amount of that time is formed by the contribution of background activity in a virtual environment. The following trait of this activity directly connected to the society smartphonization process should be noted-its principal implementation in parallel with "real" activities (that are replete with new contents for individuals). Geovisualization allows to distinguish different combinations of foreground and background activity types:

- travel by the means of transport or by foot in physical space in parallel with different actions in a virtual one (in this case "real" activities acquire new contents that prompt individuals to view such combination as an activity with a high "added value"8);

- study and activities in a virtual environment (it is demonstrated in the daily activity cycle in Fig. 4), when background activity may appear be both the former and the latter; for example, top-priority online communication during a lecture is a telling illustration of bringing activity in virtual space to the forefront;

Student (female, aged 19)

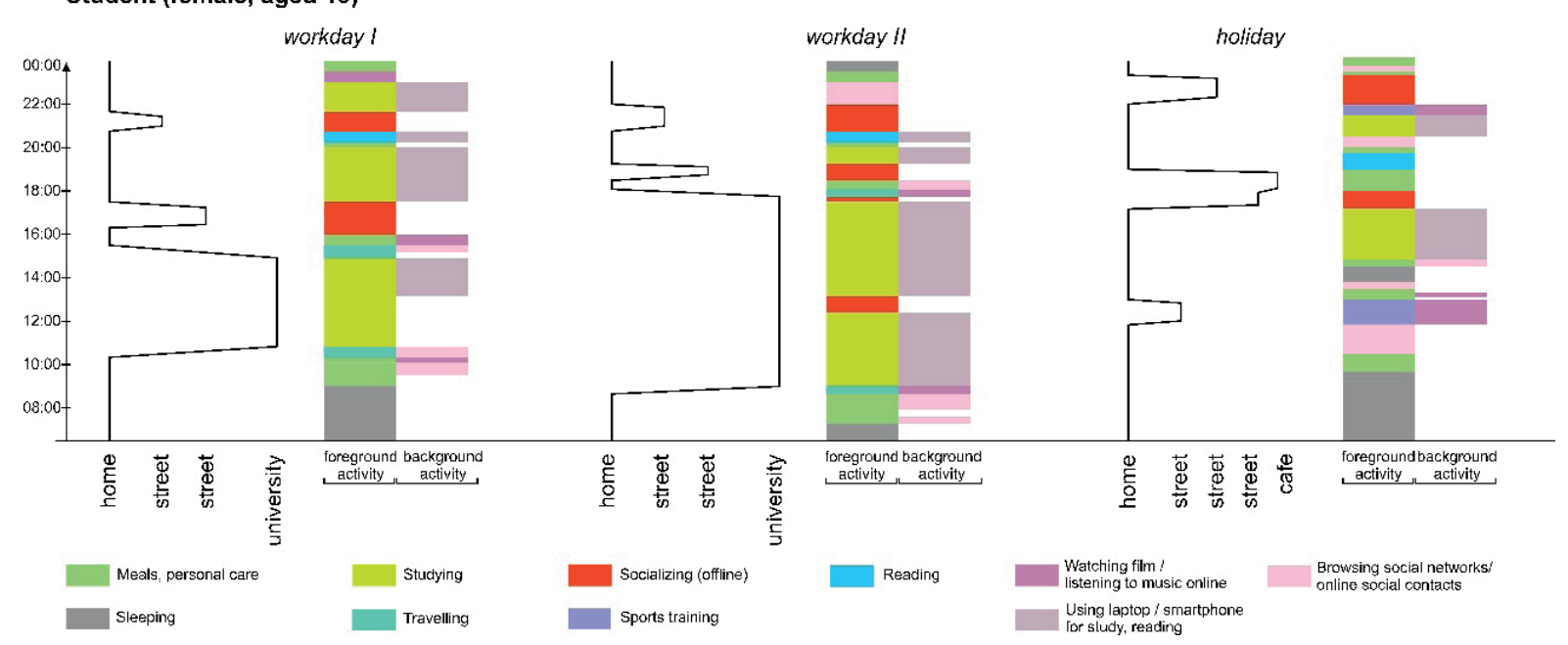

Fig. 3. Daily cycle of foreground and background activities of the respondent (a female student aged 19). Based on materials from the respondent's dairy

Student (male, aged 22)

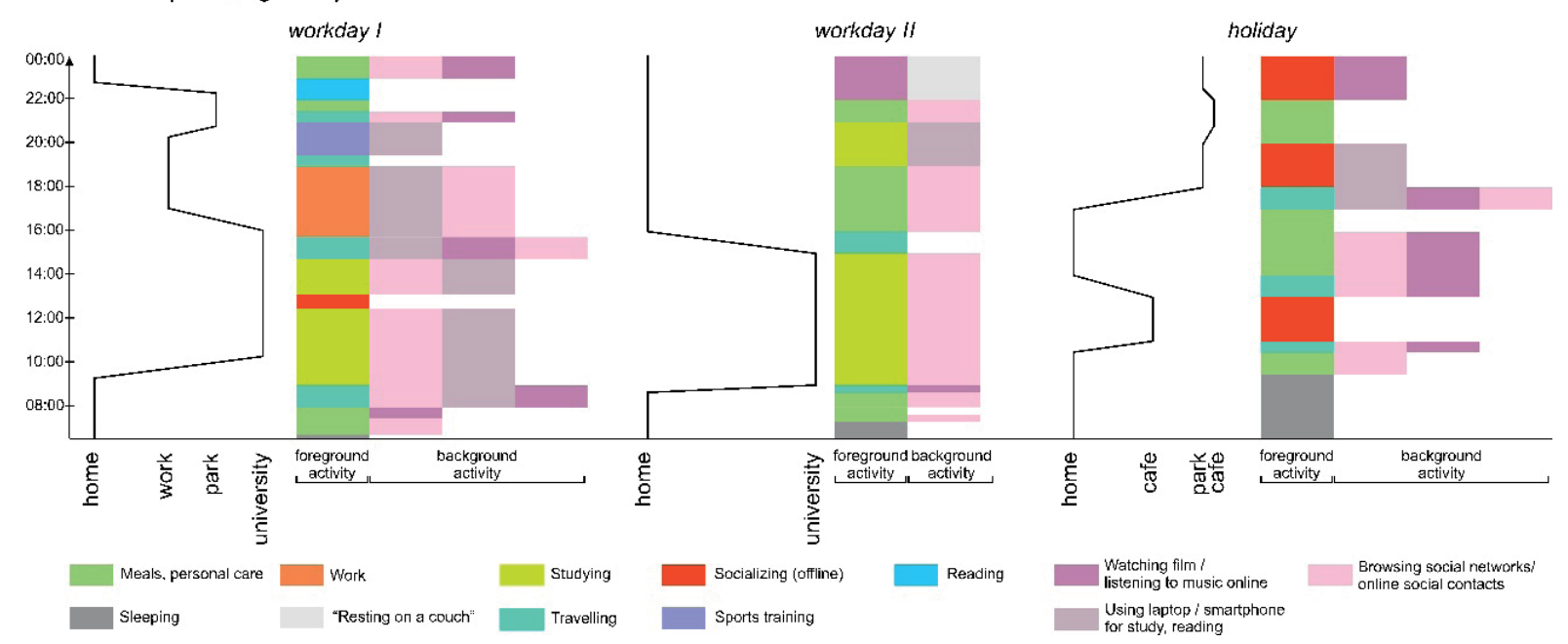

Fig. 4. Daily cycle of foreground and background activities of the respondent (a male student aged 22). Based on materials from the respondent's dairy

'There are two ways of judging the time spent on the way: (1) time spent on the way from location A to destination B as 'sacrifice' to transcend this distance; (2) adding a value to this time due to multitasking capability (to cover a distance doing something else at the same time). In the future increase in travel time can become a positive process because of mobile technologies, which will make it more useful and productive (Ben-Elia et al. 2018). 
- work and online communication in social networks (Fig. 4, workday I);

- sports activities together with listening to music or watching online instructional video clips (Fig. 3, holiday);

- activities in virtual space during meals or "resting on a couch" (Fig. 4, workday II).

Therefore, an important feature for human existence in cyberspace becomes the dynamic interstructuring of virtual and actual environments. Depending on personal perception of current developments' importance, the virtual environment may be considered as a foreground activity and actual activity_as a background one (for example, top-priority online communication during the lecture and, obviously, on the background of it).

Nonetheless, daily life of the respondents still had time intervals when activity was exercised outside of virtual space and was not related to mobile gadgets usage. Besides sleep and time for personal hygiene, among a few such youth activity types is offline interactions with friends (though smartphonization gradually advances upon actual space, leaving a trace in a form of mutual listening to music etc.). This fact points to an important trend that looms globally': when digital technologies reach out to more and more people and become intermediaries in their communication, live interaction obtains more social value. No matter how paradoxically but namely anti-digitalization of social contacts is viewed as the new upscale trend in the field of social interrelationship, especially in the countries with many years of experience in digital sphere development (United States, Great Britain, Nordic countries). The period during which a person refrains from using any electronic devices was named "digital detox." This is a way to reduce stress and focus again on social interactions in real life, to maintain health and working efficiency (Welledits et al. 2020).

Georeferencing of activity types demonstrated that individual online-activity is localized in the following places: the place of residence, educational institutions and transport routes. At public spaces (cafes, parks, etc.) the respondents still keep "live" interaction with friends as a priority, regardless of the wireless network advancement and active $\mathrm{Wi}-\mathrm{Fi}$ coverage of the urban environment (Zaporozhets 2016). However, the complete rejection of the virtual environment does not take place even here (respondents search for information related to the topic under consideration in parallel to a conversation, etc.).

\section{CONCLUSIONS}

Smartphone has a special place in the life of a modern human. Being a product of technological progress, it is becoming a guide to high-tech solutions for the population. Smartphonization of daily life opens the widest array of opportunities, while an unlimited number of goods and services is located at arm's length from a potential consumer. A smartphone is becoming not only and not so much an instrument of obtaining entertaining content (music, movies, computer games) which it was initially. Entertainment is pushed out by service applications, and even work tasks are solved with the help of mobile gadgets and not PCs or laptops.

The social environment is changing in a fundamental way. If previously communication between people was obstructed by a spatial disengagement, now this connection can be maintained permanently by social networks and instant messenger services. Moreover, social contacts can be maintained above not only spatial but language, cultural and other barriers. The usage of digital devices and virtual social interaction is growing during the crisis situations like the COVID-19 pandemic: it provides the user with the opportunity to work and study, do shopping, obtain entertaining content, interact with friends while staying in isolation. On the other hand, it leads to significant users' digital behavior changes (not always positive), the consequences of which humanity has yet to evaluate.

In the course of digitalization, a transformation of traditional types of activities is taking place. It generates new forms and gives rise to changes in the organization of human daily actions, including their subsequence, intermittency and execution frequency. Deep immersion into cyberspace starts up from parallel processing (overlapping) of actions executed in the actual and virtual world. In this case, background activity in the latter one usually steps forward, i.e., "life" in online-space becomes more important that "physical" existence (the reverse side of this process is a tendency towards the growth of importance and stature of the physical environment as a healthy lifestyle as opposed to digital addictions).

A geographical analysis of phenomena discussed above is bound with bringing in approaches and methods adequately reflecting deep penetration of digital technologies in daily life. Concurrently, one of the most important questions is the one about the possibilities of their geovisualization. The use of theoretical and applied achievements of new time geography (in combination with other geographical and sociological methods) allows examining individual foreground and background activities, specifying localization of different types of such activities, their relation, etc.

Despite the smartphonization, even youth - the most active user of digital devices, the Internet and online social networks-retain time intervals that are not related to actions in virtual space. Online activity of youth is localized in places of residence, study and on transport routes. Public spaces act as platforms for "live" communication (but a complete rejection of virtual activity is not happening there). 


\section{REFERENCES}

Abdrakhmanova G., Vishnevskiy K. et al. (2019). Digital Economy Indicators in the Russian Federation: 2019: Data Book. National Research University Higher School of Economics. Moscow: HSE.

Aralina A.V., Ben'ko E.V. (2015). Youth and the Internet. Science and Education Today, №1. (in Russian). Available at: https://cyberleninka. ru/article/n/molodezh-i-internet [Accessed 21 May 2020].

Ben-Elia E., Lyons G., Mokhtarian P.L. (2018). Epilogue: the new frontiers of behavioral research on the interrelationships between ICT, activities, time use and mobility. Transportation, Volume 45, 479-497, DOI: 10.1007/s11116-018-9871-x.

Blanutsa V.I. (2019). Territorial Structure of the Russian Digital Economy: Preliminary Delimitation of Smart Urban Agglomerations and Regions. Regional Research of Russia, №9, 318-328, DOI: 10.1134/S207997051904004X.

Brandon J. (2017). The Surprising Reason Millennials Check Their Phones 150 Times a Day. Available at: https://www.inc.com/johnbrandon/science-says-this-is-the-reason-millennials-check-their-phones-150-times-per-day.html [Accessed 21 May 2020].

Carlstein T., Parker D., Thrift N.J. eds. (1978). Timing space and spacing time. London, Edward Arnold.

Couclelis H. (2009). Rethinking time geography in the information age. Environment and Planning, A 41(7), 1556-1575.

Demidova E.E. (2018). Features of digitalization in countries of Scandinavia. Problems of the activities of scientists and research teams. Materials of the XXXI session of the International School of Sociology of Science and Technology, Vol. XXXIV, Saint Petersburg, 191-199. (in Russian). 2020].

Digital 2020: April Global Statshot. Available at: https://datareportal.com/reports/digital-2020-april-global-statshot [Accessed 21 May

Digital 2020: Global Digital Overview. Available at: https://datareportal.com/reports/digital-2020-global-digital-overview [Accessed 21 May 2020].

Ellegård K. (1999). A time-geographical approach to the study of everyday life of individuals-a challenge of complexity. GeoJournal, №48, 167-175.

Ellegård K. (2018) Thinking Time Geography: Concepts, Methods and Applications. Routledge. London.

Gillespie A., Richardson R. (2000). Teleworking and the city: myths of workplace transcendence and travel reduction. In: Wheeler J.O.,

Aoyama Y., Warf B. eds. Cities in the telecommunications age: the fracturing of geographies. Routledge, New York, 229-245.

Hägerstrand T. (1985). Time geography: focus on the corporeality of man, society, and environment. In: The Science and Praxis of Complexity. Tokyo, Japan: United Nations University, 193-216.

Hägerstrand T. (1970). What about people in regional science? Papers of the Regional Science Association, №24, 7-21.

Hallin P.O. (1991). New Paths for Time geography? Geografiska Annaler, Series B, Human Geography, Vol. 73, №3, $199-207$.

Janelle D.G. (1973). Measuring human extensibility in a shrinking world. The Journal of Geography, №75(5), 8-15.

KramerC. (2004).Verkehrsverhalten und Mobilität. In: Alltag in Deutschland. Analysenzur Zeitverwendung. BeiträgezurErgebniskonferenz

der Zeitbudgeterhebung, 2001/02. Statistisches Bundesamt, Bd. 43, 23-38.

Kwan M.-P. (2001). Cyberspatial cognition and individual access to information: the behavioral foundation of cybergeography. Environment and Planning, B. 28(1), 21-37.

Lenntorp B. (1976). Paths in Space-Time Environments: A Time-Geographic Study of Movement Possibilities of Individuals. The Royal

University of Lund, Sweden, CWK Gleerup.

Lenntorp B. (1999). Time geography: at the end of its beginning. GeoJournal, №48(3), 155-158.

Ling R. (2012). Taken for grantedness: the embedding of mobile communication into society. Cambridge, MA: MIT Press.

Markova V.D. (2019). Digital economy: new opportunities and threats for regions. Region: Economics and Sociology, 3(103), 102-115. (in Russian).

Measuring Digital Development. Facts and Figures 2019. (2019). Available at: https://www.itu.int/en/ITU-D/Statistics/Documents/facts/ FactsFigures2019.pdf [Accessed 21 May 2020].

Nagirnaya A.V. (2018). Innovative-informational polarization of Russia on the example of the Internet. Problems of economic sciences, №6, 36-42. (in Russian).

Pred A. (1977). The Choreography of Existence: Comments on Hägerstrand's Time geography and Its Usefulness. Economic Geography, Vol. 53, №2, 207-221.

Shaw Sh.-L., Yu H. (2009). A GIS-based time-geographic approach of studying individual activities and interactions in a hybrid physicalvirtual space. Journal of Transport Geography, №17, 141-149.

Smartphone ownership is growing rapidly around the world, but not always equally. (2019). Available at: https://www.pewresearch.org/ global/wp-content/uploads/sites/2/2019/02/Pew-Research-Center_Global-Technology-Use-2018_2019-02-05.pdf [Accessed 21 May 2020].

Starikova A.V., Treivish A.I. (2017). Time, place and mobilities: evolution of time geography. Regional Research, №3, 13-22. (in Russian).

Thulin E., Vilhelmson B. (2019). Bringing the background to the fore: time geography and the study of mobile ICTs in everyday life. In: Time geography in the Global Context. K. Ellegård (ed.). Abingdon and New York, NY: Routledge, 96-112.

Thulin E., Vilhelmson B., Schwanen T. (2019). Absent Friends? Smartphones, Mediated Presence, and the Recoupling of Online Social Contact in Everyday Life. Annals of the American Association of Geographers.

Welledits V., Schmidkonz C., Kraft P. (2020). Digital Detox im Arbeitsleben. Methoden und Empfehlungen für einen gesunden Einsatz von Technologien. Wiesbaden: Springer, DOI: 10.1007/978-3-658-28071-0.

Zaporozhets O.N. (2016). Digital cave: policies and practices of Internet using in the metro. Bulletin of the Lobachevsky State University of Nizhni Novgorod, Series: Social Sciences, №4, 148-157. (in Russian). 